\title{
CSF2 Overexpression Is Associated with STAT5 Phosphorylation and Poor Prognosis in Patients with Urothelial Carcinoma
}

\author{
Yi-Ying Lee ${ }^{1}$, Wen-Jeng Wu 2,3,4,5, Chun-Nung Huang2,3,5, Ching-Chia Li 2,3,4,5, Wei-Ming Li 2,3,5, Bi-Wen \\ $\mathrm{Yeh}^{2,3,5}$, Peir-In Liang7, Ting-Feng $\mathrm{Wu}^{8}$, Chien-Feng Li8, $8,10,11 \bowtie$ \\ 1. Department of Pathology, Chi Mei Medical Center, Liouying, Tainan, Taiwan; \\ 2. Department of Urology, Faculty of Medicine, Kaohsiung Medical University; \\ 3. Department of Urology, Kaohsiung Medical University Hospital, Kaohsiung Medical University; \\ 4. Department of Urology, Kaohsiung Municipal Ta-Tung Hospital; \\ 5. Center for Stem Cell Research, Kaohsiung Medical University, Kaohsiung, Taiwan; \\ 6. Department of Internal Medicine, Kaohsiung Medical University Hospital, Kaohsiung Medical University; \\ 7. Department of Pathology, Kaohsiung Medical University Hospital, Kaohsiung Medical University; \\ 8. Department of Biotechnology, Southern Taiwan University of Science and Technology, Tainan, Taiwan; \\ 9. National Institute of Cancer Research, National Health Research Institutes, Tainan, Taiwan; \\ 10. Graduate Institute of Medicine, College of Medicine, Kaohsiung Medical University, Kaohsiung, Taiwan; \\ 11. Division of Clinical Pathology, Chi Mei Medical Center, Tainan, Taiwan. \\ $\square$ Corresponding author: Chien-Feng Li, MD, PhD. Department of Pathology, Chi Mei Medical Center, Tainan, Taiwan. E-mail: angelo.p@yahoo.com.tw.
}

( ) Ivyspring International Publisher. Reproduction is permitted for personal, noncommercial use, provided that the article is in whole, unmodified, and properly cited. See http://ivyspring.com/terms for terms and conditions.

Received: 2015.11.01; Accepted: 2016.01.22; Published: 2016.03.26

\begin{abstract}
Background: Urothelial carcinoma (UC) commonly occurs in the urinary bladder (UB) and rarely in upper the upper urinary tract (UT). Its molecular pathogenesis, however, remains obscure. Though the constitutive phosphorylation of Signal Transducer and Activator of Transcription 5 (STAT5) is an important part of carcinogenesis generally, researchers have not systematically investigated this process specifically in relation to UC. The present study addresses this gap. Through data mining a published transcriptomic database of UBUCs (GSE32894), it identified Colony Stimulating Factor 2 (CSF2) as the stepwise upregulated gene of much significance among those related to the positive regulation of tyrosine phosphorylation of STAT5 (GO:0042523). Since the phosphorylation of STAT5, a key process in the development of UC, is closely associated with CSF2, we then examine CSF2 transcript and protein expression, justifying their association with clinicopathological features and survival in our well-established cohort of patients with UC.

Design: Laser capture microdissection in conjunction with real-time qRT-PCR are used to detect CSF2 transcript levels in 24 UBUCs and 6 non-tumor urothelium samples. We then used the $\mathrm{H}$-score method to evaluate the immunohistochemistry in order to determine CSF2 protein expression in 296 UBUCs and 340 UTUCs, respectively. After correlating protein expression status with key clinicopathological features, the prognostic significance of CSF2 protein expression was determined for disease-specific survival (DSS) and metastasis-free survival (MeFS).

Results: We exclusively detected the CSF2 transcript, which was stepwise upregulated in tumor lesions $(p=0.010)$. In both groups of UC we found overexpression of CSF2 significantly related to incremental $p T$ status (UTUC, $p=0.011$; UBUC, $p<0.001$ ), as well as with perineural invasion (UTUC, $p=0.002$; UBUC, $p=0.001$ ). Univariate analysis found a close correlation between CSF2 overexpression and unfavorable prognosis for both DSS (UTUC, $p=0.0001$; UBUC, $p<0.0001$ ) and MeFS (UTUC, $p=0.0001 ;$ UBUC, $p=0.0002$ ). High expression of $C S F 2$ still remained prognostically for DSS (UTUC, $p=0.015$; UBUC, $p=0.004$ ) and MeFS (UTUC, $p=0.008$; UBUC, $p=0.027$ ) in multivariate comparison.
\end{abstract}


Conclusion: Our data showed that overexpression of CSF2 was inferred in advanced disease status and poor clinical outcomes for both UTUC and UBUC patients, suggesting that CSF2 may serve as an important prognosticator and a potential therapeutic target of UC.

Key words: CSF2, Colony Stimulating Factor 2, urinary bladder, upper tract, urothelial carcinoma.

\section{Introduction}

Urothelial carcinoma (UC) is the most common epithelial neoplasm arising from the entire urothelium of the urinary tract including upper urinary tract descending to distal urethra. Of these anatomic locations, urinary bladder urothelial carcinoma (UBUC) remains the most common, while upper urinary tract urothelial carcinomas (UTUC) are rare, comprising only $5 \%$ to $10 \%$ of all UCs [1]. Our analysis assumes that both UTUC and UBUC share similarities regardless of location, but some exposures seem more specific to UTUC, such as in patients with aristolochicacid-induced nephropathies as a result of either Chinese herb toxification or Balkans endemic nephropathy, in those associated with chronic phenacetin abuse, and in Blackfoot disease prevalent on the southwest coast of Taiwan [2]. Although there is a greater genetic predisposition to UTUC implicating Lynch syndrome [Hereditary non-polyposis colorectal cancer (HNPCC) syndrome] and promotor hypermethylation, it shows widely similarity for UTUC and UBUC in the molecular biology [3-5]. In addition, the behavior of both diseases is identical after adjusting for tumor stage and histological grade [6]. This may indicate that both UTUC and UBUC involve a similar tumorigenesis pathway.

STAT5 proteins play a pivotal part in this multistep process of tumorigenesis. Research has implicated their involvement in cytokine signaling, as well as in mediating the expression of specific genes dealing with cell proliferation, apoptosis, induction of cell differentiation, and inflammation. Though STAT $5 \mathrm{~A}$ and STAT $5 \mathrm{~B}$, two relevant transcription factors of the STAT5 family, are encoded by separate genes, they are $90 \%$ the same at the amino acid level [7]. Growing evidence suggests that the constitutive phosphorylation of these STAT5 proteins plays a key role in oncogenesis, and they have been closely connected to human cancers including a majority of leukemias and several kinds of malignancies such as breast, prostate, and head and neck cancers [8-11]. Nevertheless, fibroblast growth factor receptor-3 (FGFR3), a member of tyrosine kinase receptor family, is found to be implicated in the tumorigenesis of multiple cancers including UBUCs and other urothelial cancers $[12,13]$. Besides, it could stimulate phosphatidylinositol 3-kinase (PI3K) and STAT, ensuing activation of the STAT pathway [14]. Despite this knowledge, however, the activation mechanism of STAT5 has not been systemically investigated in UC $[15,16]$. This we will accomplish with our analysis of these well-known transcription factors and their place in UBUC tumor development.

By performing data mining from a published transcirptomic dataset of UBUCs (GSE32894), we have clarified colony stimulating factor 2 gene (CSF2, granulocyte macrophage-colony stimulating factor), as the most upregulated gene of significance for tumor development and invasiveness among those associated with positive regulation of tyrosine phosphorylation of STAT5 (GO:0042523). CSF2 is a cytokine functioning as hematologic cell growth factor that operates by stimulating stem cells to produce granulocytes and monocytes; though STAT5 can be activated by several cytokines and hormones including interleukins (IL-2, IL-3, IL-5 and IL-7), thrombopoietin, erythropoietin, growth hormone, insulin and prolactin, it is the preferred member of the STAT family activated by CSF2 [9, 10, 17-22]. CSF2 also activates at least three signaling pathways: the Janus kinase (JAK) 2/STAT pathway [19-21], the ras/mitogen-activated protein kinase (MAP kinase) pathway [22], and the PI3K pathway [23]. In this light, an examination of STAT 5 proteins on the tumorigenesis of UBUCs demands a comprehensive analysis of CSF2 transcript and protein expression. Furthermore, we also examined the associations of CSF2 transcript and protein expression with clinicopathological parameters and disease-survival in our well-estalished cohort of UC.

\section{Materials and Methods}

\section{Analysis of published transcriptomic database}

To identify genes pivotal in pathogenesis and tumor invasiveness in $\mathrm{UC}$, data mining by use of the GEO (National Center Biotechnology information, Bethesda, MD, USA) was done. One dataset, GSE32894 (http://www.ncbi.nlm.nih.gov/geo/ query/acc.cgi?acc $=$ GSE32894 ) analyzing radical cystectomy tissues from 308 UBUCs by the use of v3.0 of Illumina HumanHT-12 expression beadchip, was recognized. The raw CEL files that were imported into Nexus Expression 3 software (BioDiscovery) were 
utilized to computerize the expression level. There was no preselection or filtering in all probe sets for the analysis. We used supervised comparative analysis and functional profiles to analyze which transcripts were differentially expressed with statistical significance, focusing on pathways associated with positive regulation of tyrosine phosphor-STAT5 (GO:0042523), based on primary tumor status (pT) and distant metastasis. Those differentially expressed between high-stage (pT2-pT4) UC with metastasis and low-stage (pTa-pT1) UC without metastasis was compared for further analysis. Genes with significantly differential expression $(p<0.001)$ were chosen. All enrolled 308 cases were dichotomized to high- and low-expression clusters for further survival analysis to computerize the potential valuable prognosticators of selected genes.

\section{Patients and tumor specimens}

After obtaining the approval of the institutional review board (IRB) of Chi Mei Medical Center (Tainan, Taiwan), all the using UC samples (IRB10302015) with the informed consents and sampling procurement were retrieved and analyzed from the hospital BioBank. For immunohistochemistry and survival analysis, we studied data on urothelial carcinoma cases from between 1996 and 2004 as previously described [24-26]. A total of 635 well-characterized cases were selected: 340 UTUCs and 295 UBUCs. Nephroureterectomy with resection of the bladder cuff and regional lymphadectomy were undergone in all the UTUC patients. Transurethral resection of the bladder tumor (TURBT) was performed on those who were diagnosed with superficial UBUC (pTa and pT1), with or without subsequent intravesical BCG. Patients whose tumors recurred received radical cystectomy as salvage treatment. For UBUC showing muscular invasion, radical cystectomy with bilateral pelvic lymph node dissection was done. Cisplatin-based adjuvant chemotherapy was applied to PT3 or pT4 tumor stage and/or nodal metastatic UBUC patients. Carboplatin was introduced in those with renal insufficiency. Nevertheless, there were just 29 of 106 cases with pT3 or pT4 stage and/or lymph node positive UTUC intervened by adjuvant chemotherapy. There was no application of neo-adjuvant chemotherapy to in this current cohort. The criteria evaluated for the clinicopathological features were basically the same as our previous work $[27,28]$. For UTUC, mutifocality was included for evaluation and only the most invasive lesion which showed the highest pT status was used for the classification of $\mathrm{pT}$ status. For UBUC, multifocality was not studied, but the most invasive lesion was used for the determination of pT status similarly. Those patients with synchronous UTUC and UBUS were carefully excluded. The mean follow-up duration for UTUTC and UBUC was $44.7 / 30.8$ months while the median interval was 38.9/23.1 months for each UCs. Histopathological diagnosis of each case was reappraised by two pathologists (I.W.C and C.F.L) on hematoxylin-eosin (H\&E) sections according to the current World Health Organization/International Society of Urologic Pathology consensus classification [12]. The vascular invasion was defined as the presence of tumorous thrombi/emboli in the endothelium-lined vascular channel and the perineural invasion was determined by cancer cells wrapping the nerve bundles. Both were directly observed on H\&E slides. Low and high mitotic activity were determined by the mitotic rate which was achieved by calculating mitotic counts per 10 high-power fields (HPFs; 400x light microscopic magnification). It is defined as low mitotic rate with a mitotic rate less than 10/10 HPFs, and high mitotic activity with a rate 10 or more. Another independent cohort using 24 fresh UBUC samples was introduced, with a high content of tumorous tissue and 6 non-tumorous urothelial samples, and was selected for determination of CSF2 mRNA expression detected by real-time RT-PCR assay. Twelve cases fall into pTapT1 and the remaining 12 cases to pT2 and higher stages.

\section{Real-time RT-PCR}

The archived frozen tissue was carefully examined to obtain twenty-four UBUC cases with a high tumor percentage of more than $70 \%$. For quantification, total RNAs from these cases were extracted for reverse-transcription. Pre-designed TaqMan probe targeting CFS2 (hs00929873_m1, Applied Biosystems) was performed to measure the mRNA amount with the ABI StepOnePlus ${ }^{\mathrm{TM}}$ System as described in our previous studies [28, 29]. Followed by the internal control of normalization to POLR2A (Hs01108291_m1), the expression folds of CSF2 was calculated to show association with normal urothelium by comparative $C_{t}$ method.

\section{Immunohistochemical staining CSF2 and phosphor-STAT5}

After histopathological review for immunohistochemistry, we selected representative tissue blocks with the deepest invasiveness for each case. Tissues retrieved from paraffin-embedded sections were cut at $4-\mu \mathrm{m}$ thickness, followed by deparaffinization with xylene, rehydration with ethanol, and the retrieval of antigen. The endogenous peroxidase was quenched by saline for 15 minutes 
and then incubated with primary monoclonal antibodies against CSF2 (1:100, Cat. No. ab77768, rabbit polyclonal, abcam, Cambridge, MA) and phosphor-STAT5 (pSTAT5, Tyr 694/Tyr 699) (1:50, Cat. No. sc-11761, goat polyclonal, Santa Cruz, CA) for an hour. DAKO ChemMate EnVision Kit (K5001, Carpinteria, CA, USA) was used for detecting these primary antibodies. Target cells expressing brown cytoplasmic chromogen were shown to have immunopositivity. The normal urothelium was used as the positive control, while no incubated primary antibody served as a negative control.

\section{Assessment and scoring of CSF2 and pSTAT5}

CSF2 and pSTAT5 immunoexpression was generated by two pathologists (I.W.C \& C.F.L) blinded to patients' clinical information. A histological score (H-score) was obtained by assessing both the percentage and staining intensity of cancer cells with cytoplasmic expression of CSF2. It was calculated briefly by the use of the equation as belowe: $\mathrm{H}$-score $=\Sigma P_{i}(i+1)$, where $i$ is the intensity of stained cancer cells (ranging from 0 to $3+$ ), and $P i$ is the percentage of positive-stained cancer cells of intensity from $0 \%-100 \%$. The generated score ranged from 100-400. $0 \%$ of tumor cells with immunopositivity denoted 100 and $100 \%$ of cancer cells expressed strong immunostaining (3+) represented 400 , the same scoring criteria as reported previously $[28,30,31]$.

\section{Statistical analysis}

SPSS v14.0 software package (SPSS Inc. Chicago, IL, USA) was performed for statistical analyses. Median H-score of CSF2 as cutoff was determined to dichotomize patients into high- and low-expression clusters. It were examined the associations of CSF2 expression status with clinicopathological variables using the chi-square test. The endpoints analyzed were DSS and MeFS which were decided since the commencement of curative surgery to the date an event developed. Those with loss of follow-up were decided primarily on the latest appointment. Survival curves were plotted by the use of Kaplan-Meier method and evaluated prognostic differences between groups by the log-rank test. For those with $p$-values less than 0.05 at the univariate level, the parameters were then joined into multivariate tests by the use of the Cox proportional hazards model. Two-sided tests was used with $p<0.05$ that was considered statistically significant.

\section{Results}

CSF2 as a differentially upregulated transcript of significance relating to positive regulation of tyrosine phosphorylation of STAT5 in UBUC

From the validation dataset of 308 cases (GSE32894), we focused on nine probes covering eight transcripts implicated in the positive regulation of tyrosine phosphorylation of STAT5 (GO:0042523). Among these, there were only two probes containing two genes significant differentially expressed in increment of pT stage and metastatic events, including the upregulation of CSF2 and IGF (Fig. 1 and Table 1). Nonetheless, CSF2 stands for the most significantly implicated, with a $\log 2$ ratio of 0.4506-fold upregulation associated with incremental pT status. Interestingly, CSF2 also shows a stepwise increment from pTa to $\mathrm{pT} 1$ and from $\mathrm{pT} 1$ to pT2-T4 lesions with $\log 2$ ratios of $0.2204(\mathrm{p}=0.0048)$ and $0.2130 \quad(p=0.0157)$, respectively. These findings prompted us to justify whether the CSF2 expression was of significance in this current cohort of UCs. Moreover, we also explored the relation between CSF2 expression and STAT5 phorphorylation and its significance.

\section{Clinicopathological findings for UTUC}

The clinicopathological parameters of the UTUC cases were enclosed in Table 2. There was no evident gender preference, with a median of 68 years at initial diagnosis (34-87 years). Sixty-two cases (18.2\%) presented with multifocal diseases, 49 (14.4\%) of which showed synchronously tumor involvement of the renal pelvis and ureter. There were 284 patients (83.5\%) with high histological grade and 159 (46.8\%) with advanced pT stage (pT2-T4). Frequent mitoses were detected in nearly half of the patients $(n=167$, $49.1 \%) .106$ cases (31.2\%) exhibited vascular invasion while only $19(5.9 \%)$ had perineurial invasion. Nodal involvement was identified in 28 cases with UTUCs $(8.2 \%)$.

\section{Clinicopathological findings for UBUC}

As shown in Table 2, male sex accounted for $73.2 \%$ of UBUC patients $(n=216)$, most of which were elder than 60 years $(n=214,72.5 \%)$. The majority of these patients $(n=239,81 \%)$ showed severe histological grade, and less than half $(n=123,41.7 \%)$ presented with advanced stage (pT2-T4). 156 cases $(52.9 \%)$ were found to have high mitotic activity formerly defined as $\geq 10$. Nodal metastasis was found in 29 patients $(23.6 \%)$. Vascular invasion was detected in $16.6 \%(n=48)$ of patients and perineurial invasion was found only in $6.8 \%$ of patients $(n=20)$. 
Figure 1. Analysis of gene expression from a published transcriptome in UBUC (GSE32894) focusing on pathways related to positive regulation of tyrosine phosphorylation of STAT5 (GO:0042523). It shows CSF2 as the most significant gene that is differentially expressed with higher tumor stages. In the heatmap, different PT statuses obtained from tumor tissues are indicated on top, and upregulation and downregulation of genes are illustrated as a spectrum of brightness of red and green, with those unaltered coded as black.

Table 1. Summary of two significantly and differentially expressed genes related to positive regulation of tyrosine phosphorylation of PSTAT5 in the published transcriptome of UBUC (GSE32894).

\begin{tabular}{|c|c|c|c|c|c|}
\hline \multirow[t]{2}{*}{ Probe } & \multicolumn{2}{|c|}{$\begin{array}{c}\text { Comparing T2-4 } \\
\text { to Ta }\end{array}$} & \multirow{2}{*}{$\begin{array}{l}\text { Gene } \\
\text { Symbol }\end{array}$} & \multirow[t]{2}{*}{ Biological Process } & \multirow[t]{2}{*}{ Molecular Function } \\
\hline & $\log$ ratio & p-value & & & \\
\hline ILMN_1661861 & 0.4506 & $<0.001$ & CSF2 & $\begin{array}{l}\text { immune response, myeloid dendritic cell differentiation, positive regulation of DNA } \\
\text { replication, positive regulation of cell proliferation, positive regulation of survival gene } \\
\text { product expression, positive regulation of tyrosine phosphorylation of Stat5 protein }\end{array}$ & $\begin{array}{l}\text { cytokine activity, } \\
\text { granulocyte } \\
\text { macrophage } \\
\text { colony-stimulating } \\
\text { factor receptor binding }\end{array}$ \\
\hline ILMN_2056087 & 0.1919 & 0.006 & IGF1 & $\begin{array}{l}\text { DNA replication, Ras protein signal transduction, anti-apoptosis, branching } \\
\text { morphogenesis of a tube, cell development, cell motion, chondroitin sulfate } \\
\text { proteoglycan biosynthetic process, glial cell differentiation, glycolate metabolic process, } \\
\text { mammary gland development, multicellular organism growth, muscle hypertrophy, } \\
\text { muscle organ development, myoblast differentiation, myoblast proliferation, myotube } \\
\text { cell development, negative regulation of smooth muscle cell apoptosis, nervous system } \\
\text { development, organ morphogenesis, phosphoinositide 3-kinase cascade, } \\
\text { phosphoinositide-mediated signaling, positive regulation of DNA replication, positive } \\
\text { regulation of Ras protein signal transduction, positive regulation of epithelial cell } \\
\text { proliferation, positive regulation of fibroblast proliferation, positive regulation of } \\
\text { gene-specific transcription, positive regulation of glycolysis, positive regulation of } \\
\text { granule cell precursor proliferation, positive regulation of insulin-like growth factor } \\
\text { receptor signaling pathway, positive regulation of mitosis, positive regulation of smooth } \\
\text { muscle cell migration, positive regulation of smooth muscle cell proliferation, positive } \\
\text { regulation of transcription from RNA polymerase II promoter, positive regulation of } \\
\text { tyrosine phosphorylation of Stat5 protein, regulation of protein metabolic process, } \\
\text { regulation of steroid hormone receptor signaling pathway, satellite cell maintenance } \\
\text { involved in skeletal muscle regeneration, sensory perception of sound, signal } \\
\text { transduction, skeletal system development, water homeostasis }\end{array}$ & $\begin{array}{l}\text { growth factor activity, } \\
\text { hormone activity, } \\
\text { insulin receptor } \\
\text { binding, insulin-like } \\
\text { growth factor receptor } \\
\text { binding, protein } \\
\text { binding }\end{array}$ \\
\hline
\end{tabular}

Table 2. Association between expression of CSF2 and other important clinicopathological variables in UC.

\begin{tabular}{|c|c|c|c|c|c|c|c|c|c|}
\hline \multirow[t]{3}{*}{ Parameter } & \multirow[t]{3}{*}{ Category } & \multicolumn{4}{|c|}{ Upper Urinary Tract Urothelial Carcinoma } & \multicolumn{4}{|c|}{ Urinary Bladder Urothelial Carcinoma } \\
\hline & & \multirow[t]{2}{*}{ Case No. } & \multicolumn{2}{|c|}{ CSF2 Expression } & \multirow[t]{2}{*}{ p-value } & \multirow[t]{2}{*}{ Case No. } & \multicolumn{2}{|c|}{ CSF2 Expression } & \multirow[t]{2}{*}{ p-value } \\
\hline & & & Low & High & & & Low & High & \\
\hline \multirow[t]{2}{*}{ Sex } & Male & 158 & 87 & 71 & 0.082 & 216 & 112 & 104 & 0.339 \\
\hline & Female & 182 & 83 & 99 & & 79 & 36 & 43 & \\
\hline \multirow[t]{2}{*}{ Age (years) } & $<65$ & 138 & 65 & 73 & 0.377 & 121 & 63 & 58 & 0.587 \\
\hline & $\geq 65$ & 202 & 105 & 97 & & 174 & 85 & 89 & \\
\hline \multirow[t]{3}{*}{ Tumor location } & Renal pelvis & 141 & 80 & 61 & 0.108 & - & - & - & - \\
\hline & Ureter & 150 & 67 & 83 & & - & - & - & - \\
\hline & Renal pelvis \& ureter & 49 & 23 & 26 & & - & - & - & - \\
\hline \multirow[t]{2}{*}{ Multifocality } & Single & 278 & 142 & 136 & 0.399 & - & - & - & - \\
\hline & Multifocal & 62 & 28 & 34 & & - & - & - & - \\
\hline \multirow[t]{3}{*}{ Primary tumor $(\mathrm{T})$} & $\mathrm{Ta}$ & 89 & 55 & 34 & $0.011^{*}$ & 84 & 54 & 30 & $<0.001^{*}$ \\
\hline & T1 & 92 & 48 & 44 & & 88 & 52 & 36 & \\
\hline & T2-T4 & 159 & 67 & 92 & & 123 & 42 & 81 & \\
\hline \multirow[t]{2}{*}{ Nodal metastasis } & Negative (N0) & 312 & 160 & 152 & 0.115 & 266 & 139 & 127 & $0.030^{*}$ \\
\hline & Positive (N1-N2) & 28 & 8 & 20 & & 29 & 9 & 20 & \\
\hline \multirow[t]{2}{*}{ Histological grade } & Low grade & 56 & 34 & 22 & 0.079 & 56 & 37 & 19 & $0.008^{*}$ \\
\hline & High grade & 284 & 136 & 148 & & 239 & 111 & 128 & \\
\hline \multirow[t]{2}{*}{ Vascular invasion } & Absent & 234 & 123 & 111 & 0.160 & 246 & 136 & 110 & $<0.001^{*}$ \\
\hline & Present & 106 & 47 & 59 & & 49 & 12 & 37 & \\
\hline \multirow[t]{2}{*}{ Perineural invasion } & Absent & 321 & 167 & 154 & $0.002^{*}$ & 275 & 145 & 130 & $0.001^{*}$ \\
\hline & Present & 19 & 3 & 16 & & 20 & 3 & 17 & \\
\hline \multirow[t]{2}{*}{ Mitotic rate/ 10HPFs) } & $<10$ & 173 & 92 & 81 & 0.233 & 139 & 74 & 65 & 0.320 \\
\hline & $>=10$ & 167 & 78 & 89 & & 156 & 74 & 82 & \\
\hline \multirow[t]{2}{*}{ pSTAT5 expression } & Low & 170 & 110 & 60 & $<0.001^{*}$ & 148 & 103 & 45 & $<0.001^{*}$ \\
\hline & High & 170 & 60 & 110 & & 147 & 44 & 103 & \\
\hline
\end{tabular}

* Statistically significant 


\section{CSF2 mRNA expressing more scarcely in high tumor stage and nodal metastatic UBUC}

In 24 analyzed cases, CSF 2 mRNA showed lower expression and increased pT status $(P=0.010)$ in UBUC and significantly differentiated early-stage UBUC from non-tumor urothelium $(P=0.041)$ (Fig. 2).

\section{Correlations of immunopositivity of CSF2 and pSTAT5 with clinicopathological variables in UTUC and UBUC}

Cytoplasmic immunoreactivity of CSF2 was expressed variably in both the UTUC and UBUC (Fig. 3 ). The median H-scores of UTUC and UBUC were 205 and 210 for each. Table 2 showing dichotomized results of low and high CSF2 expression groups, increased CFS2 expression was related significantly to high pT status (UTUC, $P=0.011$; UBUC, $P<0.001$ ), nodal metastasis (UBUC, $P=0.030$ ), higher histological grade (UBUC, $P=0.008$ ), vascular (UBUC, $P<0.001$ ) and perineurial (UTUC, $P=0.002$; UBUC, $P=0.001$ ) invasions in UC. Detailed information as summarized in Table S1, high pSTAT5 expression was associated with increment of pT (UTUC, $P=0.004$; UBUC, $P<0.001$ ), nodal status (UTUC, $P=0.049$; UBUC, $P=0.004)$, and the presence of vascular permeation (UTUC, $P=0.035$; UBUC, $P=0.001$ ). Interestingly, high CSF2 expression significantly correlated with pSTAT5 expression in both UTUC and UBUC (each $P<0.001$ ), suggesting a link between CSF2 expression and STAT5 activation.

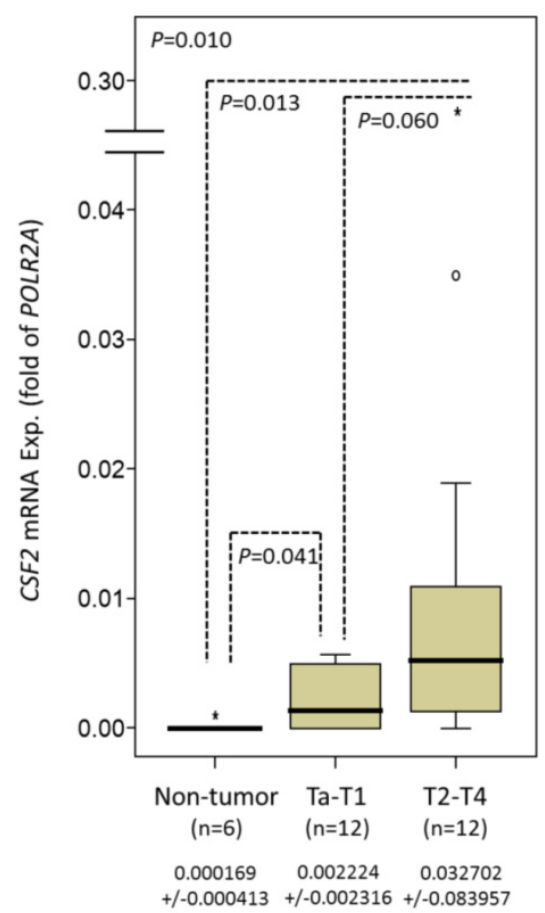

Figure 2. Quantitative real-time PCR (qPCR) analysis showing stepwise expression of CSF2 mRNA associated with significant increase in advanced primary PT status in UBUC.
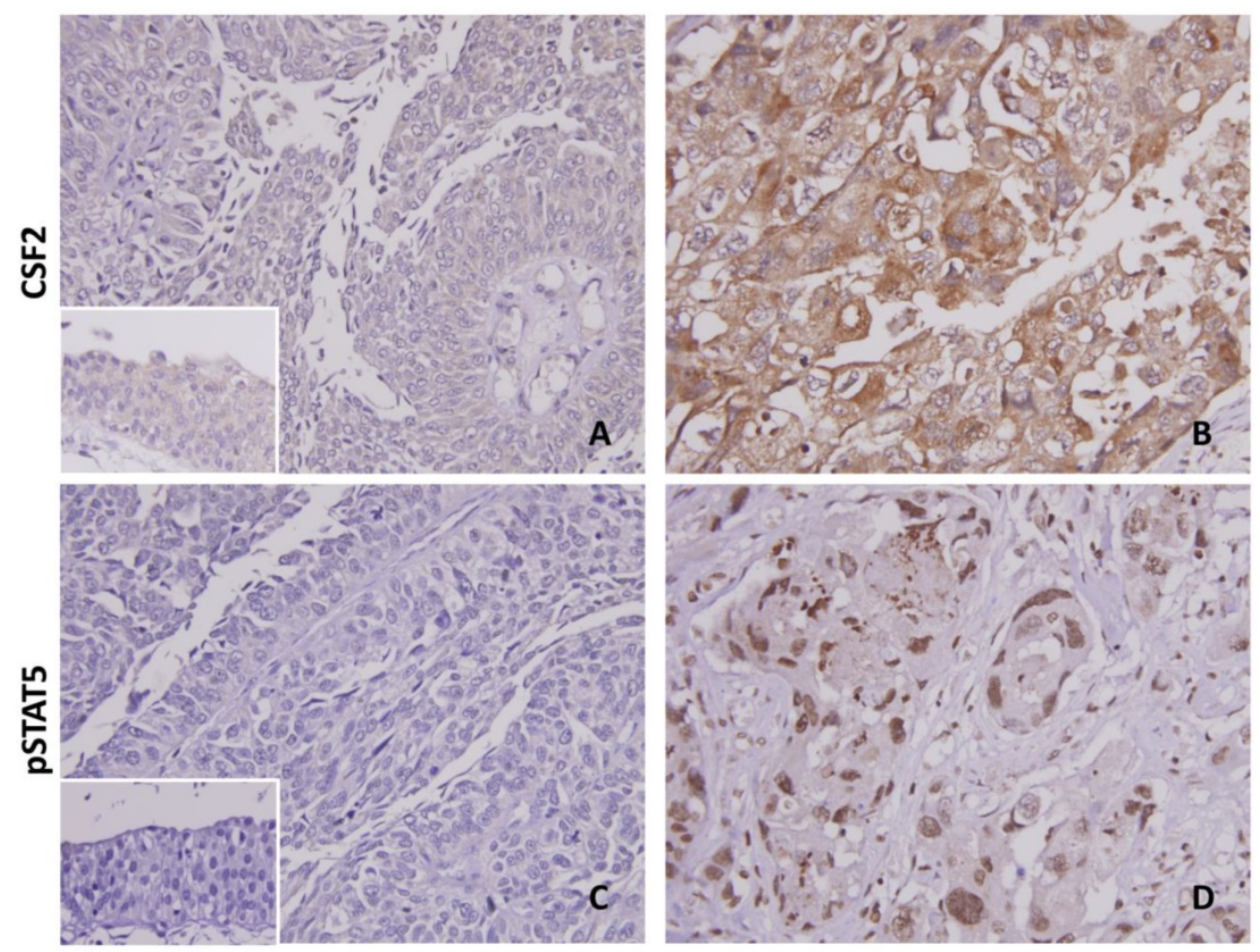

Figure 3. Both CSF2 and pSTAT5 immunostaining on representative sections of normal urothelium (A \& C) and high-grade infiltrating urothelial carcinoma (B \& D), respectively, exhibits stepwise increased expression. The non-neoplastic urothelium shows very low expression of both CSF2 and pSTAT5 (insets in A \& C). 


\section{Survival analysis for UTUC}

The median follow-up period was 38 months (ranging from 1-176 months). The clinical outcomes of UTUC patients with associated clinicopathological factors in the univariate and multivariate analyses were demonstrated in Table 3. It demonstrated that inferior DSS was significantly inferred in histological grade $(P=0.014)$, multifocality $(P=0.026)$, nodal involvement $(P<0.001)$, and perineurial invasion $(P=0.001)$ in multivariate comparison. MeFS showed similar findings. The $\mathrm{pT}$ status at presentation and vascular permeation in UTUC were only significantly implicated in inferior DSS and MeFS at the univariate analysis. Though a trend toward unfavorable clinical course, the anatomic locations of UTUCs were correlated with poor DSS at univariate analysis only.

\section{Survival analysis for UBUC}

All patients with available follow-up interval showed a median 23.1 months (ranging from 1 to 109 months). Notably, the increment of $\mathrm{pT}$ stage and mitotic rate in UBUC were significantly associated with shorter DSS $(\mathrm{p}<0.001$ and $\mathrm{p}=0.018$, respectively) and MeFS ( $p=0.001$ and $p=0.030$, respectively) in the multivariate comparison, as demonstrated in Table 4. The multivariate comparison showed no further relations to morbid DSS and MeFS for those significant parameters including histological grade, vascular and perineural invasions, and lymph node involvement identified at univariate analysis.

\section{Prognostic significance of CSF2 and pSTAT5 expression in UC}

In Table 3, cases with UTUC expressing high CSF2 cytoplasmic immunoreactivity had significantly inferior DSS ( $P=0.0001$, Fig. $4 \mathrm{~A})$ and MeFS $(P=0.0001$, Fig. 4B) in univariate analysis. Those with UBUC were observed to show similar results (Table 4, Fig. 4C, and Fig. 4D). Specifically in the multivariate comparison, it remained prognostically independent for overexpression of CSF2 with significantly shorter DSS and MeFS in all UCs (Table 3 and Table 4). Increment expression of pSTAT5 was only inferred to worse DSS and MeFS for both UTUC and UBUC in univariate analysis.

Table 3. Univariate log-rank analysis and multivariate analysis for DSS and MeFS in UTUC.

\begin{tabular}{|c|c|c|c|c|c|c|c|c|c|c|c|c|}
\hline \multirow[t]{3}{*}{ Parameter } & \multirow[t]{3}{*}{ Category } & \multirow{3}{*}{$\begin{array}{l}\text { Case } \\
\text { No. }\end{array}$} & \multicolumn{5}{|c|}{ DSS } & \multicolumn{5}{|c|}{ MeFS } \\
\hline & & & \multicolumn{2}{|c|}{ Univariate analysis } & \multicolumn{3}{|c|}{ Multivariate analysis } & \multicolumn{2}{|c|}{ Univariate analysis } & \multicolumn{3}{|c|}{ Multivariate analysis } \\
\hline & & & $\begin{array}{l}\text { No. of } \\
\text { event }\end{array}$ & p-value & R.R. & 95\% C.I. & p-value & No. of event & $\mathrm{p}$-value & R.R. & 95\% C.I. & p-value \\
\hline \multirow[t]{2}{*}{ Sex } & Male & 158 & 28 & 0.8286 & - & - & - & 32 & 0.7904 & - & - & - \\
\hline & Female & 182 & 33 & & - & - & - & 38 & & - & - & - \\
\hline \multirow[t]{2}{*}{ Age (years) } & $<65$ & 138 & 26 & 0.9943 & - & - & - & 30 & 0.8470 & - & - & - \\
\hline & $\geq 65$ & 202 & 35 & & - & - & - & 40 & & - & - & - \\
\hline \multirow[t]{3}{*}{ Tumor side } & Right & 177 & 34 & 0.7366 & - & - & - & 38 & 0.3074 & - & - & - \\
\hline & Left & 154 & 26 & & - & - & - & 32 & & - & - & - \\
\hline & Bilateral & 9 & 1 & & - & - & - & 0 & & - & - & - \\
\hline \multirow[t]{3}{*}{ Tumor location } & Renal pelvis & 141 & 24 & $0.0079^{*}$ & 1 & - & 0.798 & 31 & 0.0659 & - & - & - \\
\hline & Ureter & 150 & 22 & & 0.839 & $0.451-1.562$ & & 25 & & - & - & - \\
\hline & $\begin{array}{l}\text { Renal pelvis \& } \\
\text { ureter }\end{array}$ & 49 & 15 & & 1.124 & $0.314-4.024$ & & 14 & & - & - & - \\
\hline \multirow[t]{2}{*}{ Multifocality } & Single & 273 & 48 & $0.0026^{*}$ & 1 & - & $0.003^{*}$ & 52 & $0.0127^{*}$ & 1 & - & $0.007^{*}$ \\
\hline & Multifocal & 62 & 18 & & 3.185 & $1.476-6.875$ & & 18 & & 2.162 & $1.239-3.774$ & \\
\hline \multirow{3}{*}{$\begin{array}{l}\text { Primary tumor } \\
(\mathrm{pT})\end{array}$} & pTa & 89 & 2 & $<0.0001^{*}$ & 1 & - & 0.130 & 4 & $<0.0001^{*}$ & 1 & - & 0.251 \\
\hline & pT1 & 92 & 9 & & 3.349 & $0.715-15.681$ & & 15 & & 2.431 & $0.760-7.775$ & \\
\hline & pT2-T4 & 159 & 50 & & 4.619 & $1.025-20.810$ & & 51 & & 2.855 & $0.928-8.781$ & \\
\hline \multirow{2}{*}{$\begin{array}{l}\text { Nodal } \\
\text { metastasis }\end{array}$} & Negative (N0) & 312 & 42 & $<0.0001^{*}$ & 1 & - & $<0.001^{*}$ & 55 & $<0.0001^{*}$ & 1 & - & $0.002^{*}$ \\
\hline & Positive (N1-N2) & 28 & 19 & & 5.311 & $2.849-9.899$ & & 15 & & 2.622 & $1.544-5.348$ & \\
\hline \multirow{2}{*}{$\begin{array}{l}\text { Histological } \\
\text { grade }\end{array}$} & Low grade & 56 & 4 & $0.0215^{*}$ & 1 & - & $0.006^{*}$ & 3 & $0.0027^{*}$ & 1 & - & 0.055 \\
\hline & High grade & 284 & 57 & & 4.055 & 1.494-11.009 & & 67 & & 2.198 & $0.983-4.915$ & \\
\hline \multirow{2}{*}{$\begin{array}{l}\text { Vascular } \\
\text { invasion }\end{array}$} & Absent & 234 & 24 & $<0.0001^{*}$ & 1 & - & 0.171 & 26 & $<0.0001^{*}$ & 1 & - & $0.003^{*}$ \\
\hline & Present & 106 & 37 & & 1.515 & $0.836-2.747$ & & 44 & & 2.496 & $1.367-4.556$ & \\
\hline \multirow{2}{*}{$\begin{array}{l}\text { Perineural } \\
\text { invasion }\end{array}$} & Absent & 321 & 50 & $<0.0001^{*}$ & 1 & - & $<0.001^{*}$ & 61 & $<0.0001^{*}$ & 1 & - & $0.010^{*}$ \\
\hline & Present & 19 & 11 & & 3.923 & $1.841-8.354$ & & 9 & & 2.755 & $1.271-5.971$ & \\
\hline \multirow{2}{*}{$\begin{array}{l}\text { Mitotic rate/ } \\
10 \mathrm{HPFs}\end{array}$} & $<10$ & 173 & 27 & 0.167 & - & - & - & 30 & 0.0823 & - & - & - \\
\hline & $>=10$ & 167 & 34 & & - & - & - & 40 & & - & - & - \\
\hline \multirow[t]{2}{*}{ CSF2 expression } & Low & 170 & 17 & $0.0001^{*}$ & 1 & - & $0.045^{*}$ & 21 & $0.0001^{*}$ & 1 & - & $0.044^{*}$ \\
\hline & High & 170 & 44 & & 1.836 & $1.014-3.325$ & & 49 & & 1.756 & $1.015-3.038$ & \\
\hline \multirow{2}{*}{$\begin{array}{l}\text { pSTAT5 } \\
\text { expression }\end{array}$} & Low & 170 & 22 & $0.0108^{*}$ & 1 & - & 0.260 & 24 & $0.0022^{*}$ & 1 & & 0.092 \\
\hline & High & 170 & 39 & & 1.379 & $0.788-2.411$ & & 46 & & 1.577 & $0.928-2.681$ & \\
\hline
\end{tabular}

* Statistically significant 
Table 4. Univariate log-rank analysis and multivariate analysis for DSS and MeFS in UBUC.

\begin{tabular}{|c|c|c|c|c|c|c|c|c|c|c|c|c|}
\hline \multirow[t]{3}{*}{ Parameter } & \multirow[t]{3}{*}{ Category } & \multirow{3}{*}{$\begin{array}{l}\text { Case } \\
\text { No. }\end{array}$} & \multicolumn{5}{|c|}{ DSS } & \multicolumn{5}{|c|}{ MeFS } \\
\hline & & & \multicolumn{2}{|c|}{ Univariate analysis } & \multicolumn{3}{|c|}{ Multivariate analysis } & \multicolumn{2}{|c|}{ Univariate analysis } & \multicolumn{3}{|c|}{ Multivariate analysis } \\
\hline & & & No. of event & p-value & R.R. & 95\% C.I. & p-value & No. of event & p-value & R.R. & 95\% C.I. & p-value \\
\hline \multirow[t]{2}{*}{ Gender } & Male & 216 & 41 & 0.4446 & - & - & - & 60 & 0.2720 & - & - & - \\
\hline & Female & 79 & 11 & & - & - & - & 16 & & - & - & - \\
\hline \multirow[t]{2}{*}{ Age (years) } & $<65$ & 121 & 17 & 0.1136 & - & - & - & 31 & 0.6875 & - & - & - \\
\hline & $\geq 65$ & 174 & 35 & & - & - & - & 45 & & - & - & - \\
\hline \multirow[t]{3}{*}{ Primary tumor $(\mathrm{pT})$} & pTa & 84 & 1 & $<0.0001^{*}$ & 1 & - & $<0.001^{*}$ & 4 & $<0.0001^{*}$ & 1 & - & $0.001^{*}$ \\
\hline & pT1 & 88 & 9 & & 6.423 & 0.6959 .258 & & 23 & & 5.167 & $1.513-17.642$ & \\
\hline & pT2-T4 & 123 & 42 & & 24.365 & 2.829-209.832 & & 49 & & 7.624 & $2.251-25.831$ & \\
\hline \multirow[t]{2}{*}{ Nodal metastasis } & Negative (N0) & 266 & 41 & $0.0002^{*}$ & 1 & - & 0.387 & 61 & $<0.0001^{*}$ & 1 & - & $0.028^{*}$ \\
\hline & $\begin{array}{l}\text { Positive } \\
\text { (N1-N2) }\end{array}$ & 29 & 11 & & 1.377 & $0.680-2.789$ & & 15 & & 2.006 & $1.078-3.732$ & \\
\hline \multirow[t]{2}{*}{ Histological grade } & Low grade & 56 & 2 & $0.0013^{*}$ & 1 & - & 0.983 & 5 & $0.0007^{*}$ & 1 & - & 0.711 \\
\hline & High grade & 239 & 50 & & 1.134 & $0.230-5.597$ & & 71 & & 1.229 & $0.414-3.647$ & \\
\hline \multirow[t]{2}{*}{ Vascular invasion } & Absent & 246 & 37 & $0.0024^{*}$ & 1 & - & 0.125 & 54 & $0.0001^{*}$ & 1 & - & 0928 \\
\hline & Present & 49 & 15 & & 1.681 & $0.841-3.356$ & & 22 & & 1.029 & $0.556-1.903$ & \\
\hline \multirow[t]{2}{*}{ Perineural invasion } & Absent & 275 & 44 & $0.0001^{*}$ & 1 & - & 0.112 & 66 & $0.0007^{*}$ & 1 & - & 0.328 \\
\hline & Present & 20 & 8 & & 1.959 & $0.854-4.490$ & & 10 & & 1.449 & $0.689-3.045$ & \\
\hline \multirow{2}{*}{$\begin{array}{l}\text { Mitotic rate (per } 10 \\
\text { high power fields) }\end{array}$} & $<10$ & 139 & 12 & $<0.0001^{*}$ & 1 & - & $0.018^{*}$ & 23 & $<0.0001^{*}$ & 1 & - & $0.030^{*}$ \\
\hline & $>=10$ & 156 & 40 & & 2.275 & $1.152-4.494$ & & 53 & & 1.779 & $1.056-2.997$ & \\
\hline \multirow[t]{2}{*}{ CSF2 expression } & Low & 148 & 9 & $<0.0001^{*}$ & 1 & - & $0.003^{*}$ & 22 & $0.0002^{*}$ & 1 & - & $0.022^{*}$ \\
\hline & High & 147 & 43 & & 3.045 & $1.445-6.415$ & & 54 & & 1.837 & 1.0903 .096 & \\
\hline \multirow[t]{2}{*}{ pSTAT5 expression } & Low & 147 & 17 & $0.0086^{*}$ & 1 & - & 0.762 & 30 & $0.0307^{*}$ & 1 & - & 0.694 \\
\hline & High & 148 & 35 & & 1.101 & $0.591-2.053$ & & 46 & & 0.905 & $0.552-1.485$ & \\
\hline
\end{tabular}

* Statistically significant
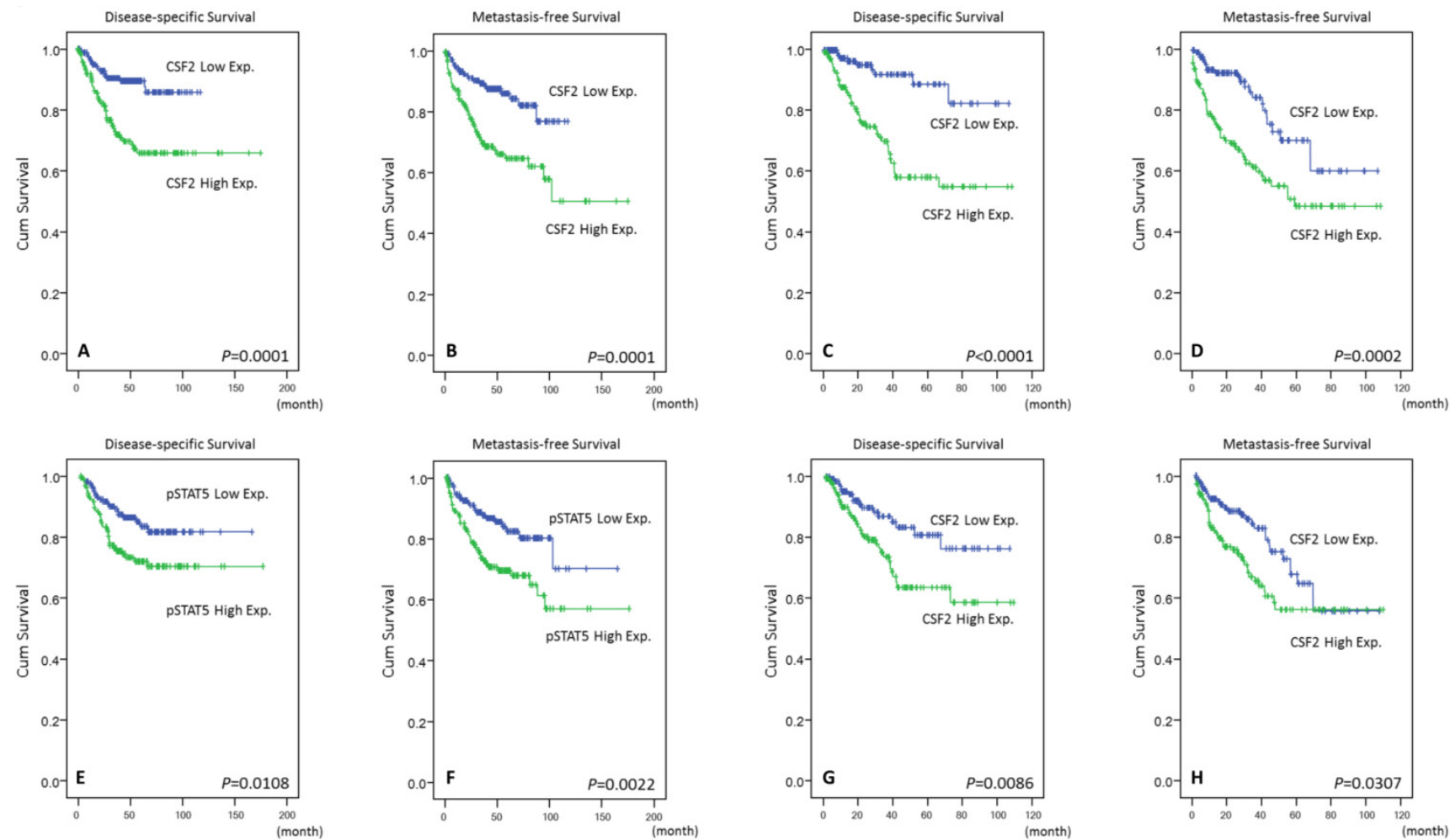

Figure 4. Kaplan-Meier plots revealing both the prognostically significant expression of CSF2 and pSTAT5 in UTUC (A \& E, DSS; B \& F, MeFS) and UBUC (C \& G, DSS; D \& H, MeFS)

\section{Discussion}

Using immunohistochemistry, we have demonstrated that the overexpression of CSF2 strongly correlates with advanced disease in both
UTUC and UBUC, including high tumor stage and identifiable perineural invasion. Furthermore, CSF2 was suggested to independently correlate with worse clinical outcomes, DSS and MeFS, in both UTUC and UBUC. These findings are in parallel with those 
observed in a variety of non-hematopoietic malignant tumors, such as lung cancers [32, 33], gliomas [34], and bladder cancers [35-37].

The cytokine CSF2 which coordinates granulopoiesis and mobilization of neutrophils to peripheral blood is secreted by fibroblasts, endothelial cells and the cells of the immune system encompassing monocytes/macrophages and activated $\mathrm{T}$ lymphocytes $[17,18]$. To initiate the intracellular signaling pathway promoting cell survival, proliferation and differentiation, a ligand-specific subunit (GM-CSFR) heamer is required. This hexamer is composed of a ligand-specific subunit (GM-CSFRa) and a beta subunit $(\beta c)$ which is shared with the IL-3 and IL-5 receptors, allowing for association with Janus kinase 2 (JAK2) [23, 38, 39]. CSF2-dependent phosphorylation of JAK2 and the subsequent recruitment of STAT5 have been suggestive of affecting cellular differentiation, and are required steps in promoting oncogenesis [10]. In the present study, both high pSTAT5 and CSF2 expression correlated with higher pT and nodal status in UTUCs and UBUCs but only CSF2 overexpression served as an inferior prognostic factor in multivariate analysis. These findings indicate that CSF2 rather than STAT predicts a poor prognosis in patients with UCs. As we know, more than $70 \%$ of papillary non-invasive UCs and $10-20 \%$ invasive UCs harbor FGFR3 mutations [12-14]. In addition, FGFR3 can directly or indirectly activate the STAT pathway, just like that in CSF2- triggering constitutive phosphorylation of STAT [14]. This may partially explain why CSF2 but not pSTAT5 is more upregulated in UCs. However, the contribution of CSF2 to cancer stem cell phenotypes is still not clear [40]. There is compelling evidence showing that various solid tumors secrete CSF2, including lung cancers, gliomas, bladder cancers, head and neck cancers, melanoma and skin carcinomas, and colorectal cancer [32-36, 41-44].

Of the tumors associated with the GM-CSF signaling pathway, we found contradictory results in different groups, some showing an anti-proliferative effect while others revealed the promotion of tumor growth [43, 45-47]. In the most frequent type of ectopically CSF2-secreted malignancy--primary and metastatic pulmonary cancers--we propose that cytokines secreted by tumor-associated endothelial cells promote angiogenesis as well as metastasis via increased expression of cell adhesion molecules [32, 33, 48]. Though not common, bladder cancers have also been found to have higher tumor grades associated with the concomitant expression of elevated CSF2 and GM-CSFR [35, 36]. Autocrine and paracrine growth stimulated by GM-CSFR might explain the aggressiveness of these mainly UC. [36]. Comparing bladder cancers to normal tissues, Sanchez-Carbayo et. al. [37] and Lee et. al. [49] have each reported microarray data indicating increased gene expression of both CSF2 and a-subunits of GM-CSFR. Our analysis, pointing to the close correlation of CSF2 overexpression in UBUCs with advanced tumor stages and poor outcomes, is consistent with Sanchez-Carbayo's and Lee's findings. Furthermore, this is the first report to date showing the overexpression of CSF2 in UTUC as well as in UBUC, thus implying that CSF2 plays a role in the progression of urothelial carcinoma.

Unlike in many other malignancies, however, ectopic secretion of CSF2 in colorectal cancers is found to display both immune-mediated and immune independent antitumor effects [45]. It has been observed that the immune-independent antitumor effect is dependent on the ectopic expression of GM-CSFR subunits of tumors [45]. Similarly, overall five-year survival is improved in patients with colorectal cancers that overexpress CSF2 and its receptor subunits. Secretion of CSF2 in melanoma and skin carcinoma has also been shown to covey antitumor effects [42, 43, 47]. CSF2 secretes a soluble VEGF receptor in transgenic mouse melanoma, further inactivating VEGF and exerting antiangiogenic effects [42]. In skin cancers, CSF2 may exhibit anti-proliferative activity via modulating VEGFR secretion and the recruitment of tumor-associated macrophages [43, 46].

Furthermore, it has been found that constitutive STAT5 signaling plays a pivotal role in the pathogenesis of vast hematological malignancies and several solid tumors [8-11]. Wang et al [50] indicated that aberrant Ras/ERK signaling results in proliferation of monocytic/granulocytic precursors, which are sufficient to induce CSF2-dependent STAT5 hypersensitivity in murine models. Furthermore, Padron et al [39] demonstrated $90 \%$ of chronic myelomonocytic leukemias with CSF2-dependent STAT5 hypersensitivity were enhanced by signaling mutations. Is it activation of the CSF2-mediated JAK-2/STAT-5 pathway that promotes maintaining tumor cell survival and/or proliferation or via autocrine secretion of CSF2 [51]? In our study, significant correlation of high expression of CSF2 with pSTAT5 expression in both UTUC and UBUC suggests a potential link between CSF2 expression and STAT5 activation. Moreover, the close correlation of CSF2 overexpression with advanced tumor stages and poor outcomes may infer an autocrine effect that plays a more important role in the maintenance of proliferation in UCs.

These findings suggest potential oncogenic 
properties and therapeutic implications related to CSF2 expression in UCs. Several therapeutic interventions targeting GM-CSF, such as Mavrilimumab (human anti-GM-CSFRa $\mathrm{Ab}$ ) and MOR103 (human anti-GM-CSF mAb), have been developing by blocking cytokine-receptor interaction and receptor activation [52, 53]. Consequently, pharmaceutical inhibition of these monoclonal antibodies might be a strategy for inactivating CSF2. In addition, there are therapeutic targets at cancer treatments with pSTAT5 are proposed for a majority of hematologic malignancies and some epithelial tumors such as prostate and breast cancers, via either indirect or direct inhibition of STAT5 activity [54, 55]. Drugs aiming at indirect inhibition of the STAT5 protein signaling pathway, such as imatinib and lestaurtinib, may result in non-specific effects of increased cell toxicity, and might be better handled by direct inhibition [56, 57]. Small molecule STAT5-SH2 domain inhibitors that prevent proper dimerization have been proposed to be one of the most potent direct, non-phosphorylated inhibitors of STAT5 [55]. These results suggest the therapeutic potential of targeting STAT5 inhibitors as adjunct to anti-GM-CSF could be used to diminish CSF2 activity in UCs that overexpress CSF2.

Last but not least, various pro- and anti-tumorigenic roles of CSF2 are addressed in different types of solid cancers. As a general rule, recombinant G- or GM-CSFs are routinely introduced to adjust cancer therapy-related neutropenia in clinical oncology. Nonetheless, adjuvant G-/GM-CSF regimen have been correlated with iatrogenic tumor growth $[58,59]$. Caution is warranted, however, and strict eligibility criteria are called for when using these recombinant cytokines in patients who require the treatment. In addition, prompt diagnosis of tumor types would aid in individualizing anticancer therapies, such as GGM-CSF-secreted vaccines for patients with melanomas and could help avoid certain adverse effects of exacerbated tumor growth in tumor cells addicted to G-/GM-CSF [46].

In conclusion, our date revealed for the first time that overexpression of CSF2 overexpression was implicated with advanced tumor status and more aggressive clinical courses. More importantly, it acts as a valuable prognostic indicator in both tumor development and progression of UC and may serve as a novel therapeutic target for treatment.

\section{Supplementary Material}

Table S1. http:/ / www.jcancer.org/v07p0711s1.pdf

\section{Abbreviations}

CSF2: Colony Stimulating Factor 2; GEO: Gene Expression Omnibus; DSS: Disease-specific survival; MeFS: metastasis-free survival; UC: Urothelial carcinoma; UBUC: Urinary bladder urothelial carcinoma; UTUC: upper urinary tract urothelial carcinoma.

\section{Acknowledgements}

This work was supported by Taiwan's Ministry of Health and Welfare (MOHW104-TDU-B-212-124-003), and Kaohsiung Medical University (KMU-TP103G01, KMU-TP103G00, KMU-TP103G04, KMU-TP103G05). This study was also supported by grants from Kaohsiung Medical University "Aim for the Top Universities (KMU-TP103E19), as well as the Biobank and grants supports from Chi Mei Medical Center.

\section{Author Contributions}

Conception and design: Y-Y Lee, W-J Wu, C-F Li; Development of methodology: C-N Huang, C-C Li, T-F Wu; Acquisition of data: C-F Li; Analysis and interpretation of data: W-M Li, B-W Yeh, P-I Liang; Writing and/or revision of the manuscript: Y-Y Lee, C-F Li; Study supervision: W-J Wu, T-F Wu, C-F Li.

\section{Competing Interests}

The authors have declared that no competing interest exists.

\section{References}

1. Siegel R, Naishadham D, Jemal A. Cancer statistics, 2012. CA Cancer J Clin. 2012; 62:10-29.

2. Yates DR, Catto JW. Distinct patterns and behaviour of urothelial carcinoma with respect to anatomical location: how molecular biomarkers can augment clinico-pathological predictors in upper urinary tract tumours. World J Urol. 2013; 31: 21-9.

3. Rouprêt M, Yates DR, Comperat E, Cussenot O. Upper urinary tract urothelial cell carcinomas and other urological malignancies involved in the hereditary nonpolyposis colorectal cancer (lynch syndrome) tumor spectrum. Eur Urol. 2008; 54: 1226-36.

4. Catto JW, Azzouzi AR, Rehman I, et al. Promoter hypermethylation is associatedwith tumor location, stage, and subsequent progression in transitional cellcarcinoma. J Clin Oncol. 2005; 23: 2903-10.

5. Zhang Z, Furge KA, Yang XJ, Teh BT, Hansel DE. Comparative gene expression profiling analysisof urothelial carcinoma of the renal pelvis and bladder. BMC Med Genomics. 2010; 3: 58.

6. Catto JW, Yates DR, Rehman I, et al. Behavior of urothelial carcinoma with respect to anatomical location. J Urol. 2007; 177: 1715-20.

7. Hanahan D, Weinberg RA. The hallmarks of cancer. Cell. 2000; 100: 57-70.

8. Grimley PM, Dong F, Rui H. Stat5a and Stat5b: fraternal twins of signal transduction and transcriptional activation. Cytokine Growth Factor Rev. 1999; 10: 131-57.

9. Nosaka T, Kawashima T, Misawa K, Ikuta K, Mui AL, Kitamura T. STAT5 as a molecular regulator of proliferation, differentiation and apoptosis in hematopoietic cells. EMBO J. 1999; 18: 4754-65.

10. Bowman T, Garcia R, Turkson J, Jove R. STATs in oncogenesis. Oncogene. 2000; 19: 2474-88.

11. Tan SH, Nevalainen MT. Signal transducer and activator of transcription 5A/B in prostate and breast cancers. Endocr Relat Cancer. 2008; 15: 367-90.

12. Eble J.N., Sauter G., Epstein J.I., Sesterhenn I.A. (Eds.): World Health Organization Classification of Tumours. Pathology and Genetics of Tumours of the Urinary System and Male Genital Organs. IARC Press: Lyon 2004.

13. Iyer G, Milowsky MI. Fibroblast growth factor receptor-3 in urothelial tumorigenesis. Urol Oncol. 2013; 31: 303-11.

14. $\mathrm{Wu}$ XR. Urothelial tumorigenesis: a tale of divergent pathways. Nat Rev Cancer. 2005; 5: 713-25. 
15. Liao Z, Lutz J, Nevalainen MT. Transcription factor Stat5a/b as a therapeutic target protein for prostate cancer. Int J Biochem Cell Biol. 2010; 42: 186-92.

16. Nikitakis NG, Siavash H, Sauk JJ. Targeting the STAT pathway in head and neck cancer: recent advances and future prospects. Curr Cancer Drug Targets. 2004; 4: 637-51.

17. Metcalf D, Begley CG, Johnson GR, et al. Biologic properties in vitro of a recombinant human granulocyte macrophage colony-stimulating factor. Blood. 1986; 67: 37-45.

18. Smith BR. Regulation of hematopoiesis. Yale J Biol Med. 1990; 63: 371-80.

19. Mui AL, Wakao H, Harada N, O'Farrell AM, Miyajima A. Interleukin-3, granulocyte-macrophage colony-stimulating factor, and interleukin-5 transduce signals through two forms of STAT5. J Leukoc Biol. 1995; 57: 799-803.

20. Feldman GM, Rosenthal LA, Liu X, et al. STAT5A-deficient mice demonstrate a defect in granulocyte-macrophage colony-stimulating factor-induced proliferation and gene expression. Blood. 1997; 90: 1768-76.

21. Kimura A, Rieger MA, Simone JM, et al. The transcription factors STAT5A/B regulate GM-CSF-mediated granulopoiesis. Blood. 2009; 114: 4721-8.

22. Bittorf $T$, Jaster R, Brock J. Rapid activation of the MAP kinase pathway in hematopoietic cells by erythropoietin, granulocyte-macrophage colonystimulating factor and interleukin-3. Cell Signal. 1994; 6: 305-11.

23. Ju"cker M, Feldman RA. Identification of a new adapter protein that may link the common beta subunit of the receptor for granulocyte/macrophage colony-stimulating factor, interleukin (IL)-3, and IL-5 to phosphatidylinositol 3-kinase. J Biol Chem. 1995; 270: 27817-22.

24. Chang IW, Lin VC, He HL, et al. CDCA5 overexpression is an indicator of poor prognosis in patients with urothelial carcinomas of the upper urinary tract and urinary bladder. Am J Transl Res. 2015; 7: 710-22.

25. $\mathrm{Li} \mathrm{CF}, \mathrm{Wu} \mathrm{WJ}, \mathrm{Wu} \mathrm{WR}$, et al. The cAMP responsive element binding protein 1 transactivates epithelial membrane protein 2, a potential tumor suppressor in the urinary bladder urothelial carcinoma. Oncotarget. 2015; 6: 9220-39.

26. Wang $\mathrm{YH}, \mathrm{Wu} \mathrm{WJ}$, Wang WJ, et al. CEBPD amplification and overexpression in urothelial carcinoma: a driver of tumor metastasis indicating adverse prognosis. Oncotarget. 2015; 6: 31069-84

27. Liang PI, Wang $\mathrm{YH}, \mathrm{Wu}$ TF, et al. IGFBP- 5 overexpression as a poor prognostic factor in patients with urothelial carcinomas of upper urinary tracts and urinary bladder. J Clin Pathol. 2013; 66: 573-82

28. Fan EW, Li CC, Wu WJ, et al. FGF7 Over Expression is an independent prognosticator in patients with urothelial carcinoma of the upper urinary tract and bladder. J Urol. 2015; 194: 223-9.

29. Li CF, Chen LT, Lan J, et al. AMACR amplification and overexpression in primary imatinib-naïve gastrointestinal stromal tumors: a driver of cell proliferation indicating adverse prognosis. Oncotarget. 2014; 5: 11588-603.

30. Li CF, Fang FM, Kung HJ, et al. Downregulated MTAP expression in myxofibrosarcoma: A characterization of inactivating mechanisms, tumor suppressive function, and therapeutic relevance. Oncotarget. 2014; 5: 11428-41.

31. Hsueh YS, Chang HH, Chiang NJ, Yen CC, Li CF, Chen LT. MTOR inhibition enhances NVP-AUY922-induced autophagy-mediated KIT degradation and cytotoxicity in imatinib-resistant gastrointestinal stromal tumors. Oncotarget. 2014; 5: 11723-36.

32. Oshika Y, Nakamura M, Abe Y, et al. Growth stimulation of non-small cell lung cancer xenografts by granulocyte-macrophage colony-stimulating factor (GM-CSF). Eur J Cancer. 1998; 34: 1958-61.

33. Lammel V, Stoeckle C, Padberg B, et al. Hypereosinophilia driven by GM-CSF in large-cell carcinoma of the lung. Lung Cancer. 2012; 76: 493-5.

34. Mueller MM, Herold-Mende CC, Riede D, Lange M, Steiner HH, Fusenig NE. Autocrine growth regulation by granulocyte colony-stimulating factor and granulocyte macrophage colony-stimulating factor in human gliomas with tumor progression. Am J Pathol. 1999; 155: 1557-67.

35. Wetzler M, Estrov Z, Talpaz M, Markowitz A, Gutterman JU, Kurzrock R. Granulocyte-macrophage colony-stimulating factor as a cause of paraneoplastic leukaemoid reaction in advanced transitional cell carcinoma. J Intern Med. 1993; 234: 417-20.

36. Perez FA, Fligner CL, Yu EY. Rapid clinical deterioration and leukemoid reaction after treatment of urothelial carcinoma of the bladder: possible effect of granulocyte colony-stimulating factor. J Clin Oncol. 2009; 27: e215-7.

37. Sanchez-Carbayo M, Socci ND, Lozano J, Saint F, Cordon-Cardo C. Defining molecular profiles of poor outcome in patients with invasive bladder cancer using oligonucleotide microarrays. J Clin Oncol. 2006; 24: 778-89.

38. Hansen G, Hercus TR, McClure BJ, et al. The structure of the GM-CSF receptor complex reveals a distinct mode of cytokine receptor activation. Cell. 2008; 134: 496-507.

39. Padron E, Painter JS, Kunigal S, et al. GM-CSF-dependent pSTAT5 sensitivity is a feature with therapeutic potential in chronic myelomonocytic leukemia. Blood. 2013; 121: 5068-77.

40. Levina V, Marrangoni AM, DeMarco R, Gorelik E, Lokshin AE. Drug-selected human lung cancer stem cells: cytokine network, tumorigenic and metastatic properties. PLoS One. 2008; 3: e3077.

41. Chen Z, Malhotra PS, Thomas GR, et al. Expression of proinflammatory and proangiogenic cytokines in patients with head and neck cancer. Clin Cancer Res. 1999; 5: 1369-79.

42. Meyer C, Sevko A, Ramacher M, et al. Chronic inflammation promotes myeloid-derived suppressor cell activation blocking antitumor immunity in transgenic mouse melanoma model. Proc Natl Acad Sci USA. 2011; 108:17111-6.
43. Obermueller E, Vosseler S, Fusenig NE, Mueller MM: Cooperative autocrine and paracrine functions of granulocyte colony-stimulating factor and granulocyte-macrophage colony-stimulating factor in the progression of skin carcinoma cells. Cancer Res. 2004; 64: 7801-12.

44. Demirci U, Coskun U, Sancak B, et al. Serum granulocyte macrophage-colony stimulating factor: a tumor marker in colorectal carcinoma? Asian Pac J Cancer Prev. 2009; 10: 1021-4.

45. Urdinguio RG, Fernandez AF, Moncada-Pazos A, et al. Immune-dependent and independent antitumor activity of GM-CSF aberrantly expressed by mouse and human colorectal tumors. Cancer Res. 2013; 73: 395-405.

46. Aliper AM, Frieden-Korovkina VP, Buzdin A, Roumiantsev SA , Zhavoronkov A. A role for G-CSF and GM-CSF in nonmyeloid cancers. Cancer Med. 2014; 3 : 737-46.

47. Roda JM, Wang Y, Sumner LA, Phillips GS, Marsh CB, Eubank TD. Stabilization of HIF-2a induces sVEGFR-1 production from tumor-associated macrophages and decreases tumor growth in a murine melanoma model. J Immunol. 2012; 189: 3168-77.

48. Chen C, Duckworth CA, Zhao Q, Pritchard DM, Rhodes JM, Yu LG. Increased circulation of galectin-3 in cancer induces secretion of metastasis-promoting cytokines from blood vascular endothelium. Clin Cancer Res. 2013; 19: 1693-704.

49. Lee JS, Leem SH, Lee SY, et al. Expression signature of E2F1 and its associated genes predict superficial to invasive progression of bladder tumors. J Clin Oncol. 2010; 28: 2660-7.

50. Wang J, Liu Y, Li Z, et al. Endogenous oncogenic Nras mutation promotes aberrant GM-CSF signaling in granulocytic/monocytic precursors in a murine model of chronic myelomonocytic leukemia. Blood. 2010; 116: 5991-6002.

51. Wang Y, Cai D, Brendel C, et al. Adaptive secretion of granulocyte-macrophage colony-stimulating factor (GM-CSF) mediates imatinib and nilotinib resistance in BCR/ABL+ progenitors via JAK-2/STAT-5 pathway activation. Blood. 2007; 109: 2147-55.

52. Burmester GR, Feist E, Sleeman MA, Wang B, White B, Magrini F. Mavrilimumab, a human monoclonal antibody targeting GM-CSF receptor-a, in subjects with rheumatoid arthritis: a randomised, double-blind, placebo-controlled, phase I, first-in-human study. Ann Rheum Dis. 2011; 70: $1542-9$.

53. Behrens F, Tak PP, Østergaard M, et al. MOR103, a human monoclonal antibody to granulocyte-macrophage colony-stimulating factor, in the treatment of patients with moderate rheumatoid arthritis: results of a phase $\mathrm{Ib} / \mathrm{II} a$ randomised, double-blind, placebo-controlled, dose-escalation trial. Ann Rheum Dis. 2015; 74: 1058-64.

54. Koptyra M, Gupta S, Talati P, Nevalainen MT. Signal transducer and activator of transcription $5 \mathrm{a} / \mathrm{b}$ : biomarker and therapeutic target in prostate and breast cancer. Int J Biochem Cell Biol. 2011; 43: 1417-21.

55. Page BD, Khoury $\mathrm{H}$, Laister $\mathrm{RC}$, et a Small molecule STAT5-SH2 domain inhibitors exhibit potent antileukemia activity. J Med Chem. 2012; 55: 1047-55.

56. Druker BJ, Tamura S, Buchdunger E, et al. Effects of a selective inhibitor of the Abl tyrosine kinase on the growth of Bcr-Abl positive cells. Nat Med. 1996; 2: 561-6.

57. Levis M, Allebach J, Tse KF, et al. A FLT3-targeted tyrosine kinase inhibitor is cytotoxic to leukemia cells in vitro and in vivo. Blood. 2002; 99: 3885-91.

58. Shaked Y, Tang T, Woloszynek $\mathrm{J}$, et al. Contribution of granulocyte colony-stimulating factor to the acute mobilization of endothelial precursor cells by vascular disrupting agents. Cancer Res. 2009; 69: 7524-8.

59. Langenberg MH, Nijkamp MW, Roodhart JM, et al. Liver surgery induces an immediate mobilization of progenitor cells in liver cancer patients: a potential role for G-CSF. Cancer Biol Ther. 2010; 9: 743-8. 